\title{
Analisis Luas Lahan Minimum untuk Memenuhi Kebutuhan Hidup Petani Padi Sawah di Kecamatan Jayapura Kabupaten OKU Timur
}

\author{
Fifian Permata Sari ${ }^{1 *}$ Munajat ${ }^{2)}$ \\ 1,2) Program Studi Agribisnis, Universitas Baturaja \\ 1) fifianpermatasari@gmail.com, ${ }^{2)}$ munajat.ub@gmail.com
}

DOI: https://doi.org/10.21107/rekayasa.v12i2.5911

\begin{abstract}
ABSTRAK
Tujuan penelitian ini adalah untuk menganalisis pendapatan, pengeluaran dan luas lahan minimum yang harus dimiliki petani padi sawah untuk dapat memenuhi kebutuhan hidupnya. Penelitian ini dilaksanakan di Kecamatan Jayapura Kabupaten OKU Timur pada bulan November sampai Desember 2018. Metode penelitian yang digunakan adalah metode survey dan penarikan contoh menggunakan acak berlapis tak berimbang. Hasil penelitian menunjukkan bahwa (1) pendapatan rata-rata petani dengan luas lahan 0,25 Ha sebesar Rp.3.852.750/mt, luas lahan 0,50 Ha, pendapatan rata-rata Rp.7.398.220/mt, luas lahan 0,75 Ha, pendapatan rata-rata Rp.13.037.100/mt, luas lahan 1 Ha, pendapatan rata-rata Rp.16.791.050/mt, luas lahan 1,25 Ha, pendapatan rata-rata Rp.21.247.000/mt, luas lahan 1,50 Ha, pendapatan rata-rata Rp.25.525.250/mt, luas lahan 1,75 Ha, pendapatan rata-rata sebesar Rp.29.366.800/mt, dan petani dengan luas lahan $2 \mathrm{Ha}$, pendapatan rata-rata Rp.32.385.000/mt. (2) pengeluaran petani dengan luas lahan 0,25 Ha sebesar Rp. 9.559.000/mt, luas lahan 0,50 Ha sebesar Rp.12.375.000/mt, luas lahan 0,75 Ha sebesar Rp.14.578.000/mt, luas lahan 1 Ha sebesar Rp.16.290.000/mt, luas lahan 1,25 Ha sebesar Rp.20.703.500/mt, luas lahan 1,50 Ha sebesar Rp.20.699.000/mt, luas lahan 1,75 Ha sebesar Rp.23.106.500/mt, dan pengeluaran petani yang memilki luas lahan 2 Ha sebesar Rp. 26.684.000/mt. (3) Luas lahan minimum yang harus diusahakan petani agar dapat memenuhi kebutuhannya adalah $1 \mathrm{Ha}$.
\end{abstract}

Kata Kunci: luas lahan minimum, kebutuhan hidup

\section{ABSTRACT}

\section{Analysis of Minimum Land Area to Meet Living Needs Paddy Farmers in Jayapura District, East OKU Regency}

The purpose of this study is to analyze the income, expense, and minimum area of land that must be cultivated by rice farmers to be able to meet their daily needs. This research was carried out in Jayapura Sub-district of OKUT Regency from November to December 2018. The research method used was the survey method and sampling using unbalanced random sampling. The results showed that (1) the average income of farmers with a land area of $0.25 \mathrm{Ha}$ is Rp.3,852,750/ $\mathrm{mt}$, land area of $0.50 \mathrm{Ha}, \mathrm{Rp} .7,398,220 / \mathrm{mt}$, land area 0,75 Ha, Rp.13,037,100/mt, land area $1 \mathrm{Ha}, \mathrm{Rp} .16,791,050 / \mathrm{mt}$, land area $1.25 \mathrm{Ha}, \mathrm{Rp} .21,247,000 / \mathrm{mt}$, land area of $1.50 \mathrm{Ha}, \mathrm{Rp} .25,525,250 / \mathrm{mt}$, land area of $1.75 \mathrm{Ha}, \mathrm{Rp} .29,366,800 /$ $\mathrm{mt}$, and land area of $2 \mathrm{Ha}$, the average income is Rp.32,385,000/mt (2) farmers' expenditure with land area of $0.25 \mathrm{Ha}$ in the amount of Rp. 9,559,000/mt, land area of $0.50 \mathrm{Ha}, \mathrm{Rp} .12,375,000 / \mathrm{mt}$, land area of $0.75 \mathrm{Ha}, \mathrm{Rp} .14,578,000 / \mathrm{mt}$, land area of $1 \mathrm{Ha}$, Rp.16,290,000/mt, area $1.25 \mathrm{Ha}$, Rp.20,703,500/mt, land area 1,5 Ha,Rp.20,699,000/mt, $1.75 \mathrm{Ha}$, Rp.23,106,500/mt, and expenditure of farmers who have 2 Ha land area, is Rp.26,684,000/mt (3) The minimum area of land that must be cultivated by farmers to be able to meet their needs is $1 \mathrm{Ha}$.

Keywords: minimum land area, necessities of life

\section{PENDAHULUAN}

Lahan merupakan sumberdaya alam yang memiliki fungsi penting dalam pembangunan suatu negara. Dalam pembangunan, hampir semua sektor memerlukan lahan seperti sektor pertanian, industri, perdagangan, dan infrastruktur. Di sektor pertanian, lahan merupakan sumberdaya yang sangat penting, baik bagi petani maupun bagi pembangunan pertanian, hal ini didasarkan pada kenyataan bahwa di Indonesia sebagai negara agraris semua kegiatan pertanian masih bertumpu pada lahan karena lahan berperan penting dalam kegiatan produksi yang dapat menghasilkan kebutuhan pangan yang dibutuhkan oleh setiap manusia (Putri, R.Z., 2015).

\section{Article History:}

Received: August, 30th 2019; Accepted: September, 29th 2019 ISSN: 2502-5325 (Online) Terakreditasi Peringkat 3 oleh Kementerian Riset, Teknologi dan Pendidikan Tinggi (ARJUNA), berdasarkan Keputusan Direktur Jenderal Penguatan Riset dan Pengembangan No: 23/E/KPT/2019 tanggal 8 Agustus 2019
Kebutuhan pangan yang diiringi dengan keberadaan petani pangan di Indonesia identik dengan menyoroti rumah tangga miskin di pedesaan. Upaya pengentasan kemiskinan pedesaan merupakan upaya peningkatan taraf hidup petani secara signifikan (Ditjen Tanaman Pangan, 2016). Di negara berkembang seperti halnya Indonesia, kehilangan lahan pertanian terjadi lebih intensif dan pertumbuhan ekonomi di luar sektor pertanian akan terjadi lebih cepat sehingga menyebabkan terjadinya transisi dalam struktur ekonomi Negara (.Azadi, H., et al. 2010). Berbagai program pemerintah dalam hal ini harus diterapkan dengan alokasi anggaran yang makin meningkat, seperti pem-

\section{Cite this as:}

Sari, F.P. \& Munajat, M. (2019). Analisis Luas Lahan Minimum untuk Memenuhi Kebutuhan Hidup Petani Padi Sawah di Kecamatan Jayapura Kabupaten OKU Timur. Rekayasa, 12(2), 157162. doi:https://doi.org/10.21107/rekayasa.v12i2.5911

(c) 2019 Universitas Trunojoyo Madura 
158 | Nazalina, A., dkk. Evaluasi Sarana Produksi Pangan Industri Tahu...

berian subsidi pupuk, peningkatan sumber daya manusia (SDM), peningkatan akses permodalan, peningkatan akses pasar, serta perbaikan teknologi. Namun demikian, upaya ini belum menolong sebagian besar petani untuk keluar dari belenggu kemiskinan. Jadi, untuk mandat pengentasan kemiskinan petani pangan perlu dicermati kembali bahwa kemiskinan di pedesaan tidak boleh hanya dilihat sebagai persoalan kultural tetapi harus dipandang sebagai persoalan struktural (Ditjen Tanaman Pangan, 2016).

Secara umum kebutuhan konsumsi rumah tangga berupa kebutuhan pangan dan nonpangan, dimana kebutuhan keduanya berbeda. Pada kondisi pendapatan yang terbatas lebih dahulu mementingkan kebutuhan konsumsi pangan, sehingga dapat dilihat pada kelompok masyarakat dengan pendapatan rendah sebagian besar pendapatan digunakan untuk memenuhi kebutuhan pangan. Namun demikian seiring pergeseran peningkatan pendapatan, proporsi pola pengeluaran untuk pangan akan menuran dan meningkatnya pengeluaran untuk kebutuhan nonpangan. Salah satu indikator tingkat kesejahteraan petani padi sawah adalah luas lahan yang diusahakan petani, apabila luas lahan yang dimiliki oleh petani lebih kecil dari luas lahan standar maka petani masih belum bisa memenuhi kebutuhannya. Luas lahan standar yang harus dimiliki petani untuk Pulau Jawa minimal $0,25 \mathrm{Ha}$, sedangkan untuk luar Pulau Jawa minimal 0,5 Ha (Mulyani, A dan Agus, F., 2017). Luas lahan berpengaruh terhadap produksi padi dan pendapatan petani. Semakin luas lahan garapan yang diusahakan petani, maka akan semakin besar produksi yang dihasilkan dan pendapatan yang akan diperoleh bila disertai dengan pengolahan lahan yang baik (Soekartawi, 2003). Terkait dengan luas lahan sektor pertanian saat ini, berdasarkan data BPS secara nasional tahun 2003-2013, selama 10 tahun luas lahan sawah mengalami penurunan yang sangat signifikan, hal ini dikarenakan beberapa faktor diantaranya alih fungsi lahan dan kebijakan pembangunan (BPS, 2013). Masalah baru yang dihadapi masyarakat yaitu berkurangnya lahan untuk melakukan usahatani sawah sedangkan jumlah penduduk semakin meningkat, sehingga rata-rata luas lahan yang dimiliki petani berada dibawah angka luas lahan minimal yaitu 0,25 $\mathrm{Ha}$ untuk pulau Jawa dan 0,5 Ha untuk luar pulau Jawa. Sektor Pertanian di Kabupaten OKU Timur mempunyai peranan penting dalam perekonomian untuk kesejahteraan petani sebagai salah satu kabupaten yang baru berkembang. Komoditi yang paling dominan di Kabupaten OKU Timur adalah padi. Berdasarkan data Badan Pusat Statistik tahun 2017, Kabupaten OKU Timur memiliki total luas lahan sawah sebesar $85.620 \mathrm{Ha}$. Hal ini ditunjukkan pada Tabel 1.

Berdasarkan Tabel 1, dapat dilihat bahwa Kabupaten OKU Timur merupakan salah satu kabupaten yang memiliki luas lahan sawah terbesar ketiga setelah Kabupaten Banyuasin dan Kabupaten Ogan Komering Ilir. Luas lahan Kabupaten
Tabel1.Luas lahan sawah menurut Kabupaten/Kota dan jenis pengairan di Provinsi Sumatera Selatan, 2017.

\begin{tabular}{clccc}
\hline \multirow{2}{*}{ No } & Kabupaten/Kota & \multicolumn{3}{c}{ Luas Lahan Sawah (Hektar) } \\
& Irigasi & Non Irigasi & Jumlah \\
$(1)$ & \multicolumn{1}{c}{$(2)$} & $(3)$ & $(4)$ & $(5)$ \\
\hline 1 & Ogan Komering & 3.244 & 5.628 & 8.872 \\
2 & Ulu & 650 & 185.348 & 185.998 \\
3 & Ogan Komering & 6.395 & 20.622 & 27.017 \\
4 & llir & 15.845 & 1.680 & 17.525 \\
5 & Muara Enim & 13.421 & 17.30 & 30.451 \\
6 & Lahat & 0 & 66.810 & 66.810 \\
7 & Musi Rawas & 0 & 226.518 & 226.518 \\
8 & Musi Banyuasin & 16.099 & 1.941 & 18.040 \\
9 & Banyuasin & 43.506 & 42.114 & 85.620 \\
10 & Ogan Komering & 0 & 67.627 & 67.627 \\
11 & Ulu Selatan & 13.105 & 986 & 14.091 \\
12 & Ogan Komering & & 6.579 & 6.579 \\
13 & Ulu Timur & 415 & 6.716 & 7.131 \\
14 & Ogan llir & 0 & 6.189 & 6.189 \\
15 & Empat Lawang & 0 & 700 & 700 \\
16 & Pali & 3.440 & 0 & 3.440 \\
17 & Musi Rawas Utara & 1.637 & 257 & 1.894 \\
& Sumatera Selatan & 117.757 & 656.745 & 774.502 \\
\hline
\end{tabular}

Sumber: BPS Sumatera Selatan Tahun 2017

Tabel 2. Luas lahan sawah menurut Kecamatan dan jenis pengairan di Kabupaten Ogan Komering Ulu Timur (Ha), 2017.

\begin{tabular}{|c|c|c|c|c|}
\hline \multirow[b]{2}{*}{ No } & \multirow[b]{2}{*}{ Kecamatan } & \multicolumn{3}{|c|}{ Luas Lahan Sawah (Ha) } \\
\hline & & Irigasi & $\begin{array}{l}\text { Non } \\
\text { Irigasi }\end{array}$ & Jumlah \\
\hline (1) & (2) & (3) & (4) & (5) \\
\hline 1 & Martapura & 50 & 1.290 & 1.340 \\
\hline 2 & Bunga Mayang & 200 & 1.117 & 1.317 \\
\hline 3 & Jayapura & 61 & 440 & 501 \\
\hline 4 & BP Peliung & 1.155 & 2.728 & 3.883 \\
\hline 5 & Buay Madang & 6.237 & 886 & 7.123 \\
\hline 6 & Buay Madang Timur & 7.539 & - & 7.539 \\
\hline 7 & BP Bangsa Raja & 2.340 & 2.519 & 4.859 \\
\hline 8 & Madang Suku II & 340 & 7.581 & 7.921 \\
\hline 9 & Madang Suku III & 2.402 & 2.766 & 5.168 \\
\hline 10 & Madang Suku I & - & 1.814 & 1.814 \\
\hline 11 & Belitang Madang Raya & 3.602 & 1.043 & 4.645 \\
\hline 12 & Belitang & 1.076 & - & 1.076 \\
\hline 13 & Belitang Jaya & 2.635 & 300 & 2.935 \\
\hline 14 & Belitang III & 5.140 & 228 & 5.368 \\
\hline 15 & Belitang II & 2.399 & 491 & 2.890 \\
\hline 16 & Belitang Mulya & 2.247 & 71 & 2.318 \\
\hline 17 & Semendawai Suku III & 434 & 1.258 & 5.562 \\
\hline 18 & Semendawai Timur & 1.799 & 2.116 & 3.895 \\
\hline 19 & Cempaka & - & 5.549 & 5.549 \\
\hline 20 & Semendawai Barat & - & 9.917 & 9.917 \\
\hline Total & & 43.506 & 42.114 & 85.620 \\
\hline
\end{tabular}

Sumber: BPS Ogan Komering Ulu Timur 2017 
OKU Timur adalah sebesar $85.620 \mathrm{Ha}$. Kecamatan Jayapura merupakan salah satu Kecamatan yang memiliki luas lahan sawah terkecil di Kabupaten OKU Timur (UPTD Kecamatan Jayapura, 2017). Luas lahan sawah menurut Kecamatan dan jenis pengairannya di Kabupaten OKU Timur ditunjukkan pada Tabel 2.

Berdasarkan Tabel 2 diatas, Kecamatan Jayapura memiliki total luas lahan sawah paling kecil, yaitu 501 hektar. Hal ini disebabkan oleh fragmentasi lahan akibat bertambahnya jumlah penduduk, bagi waris, dan dampak pembangunan. Terjadinya fragmentasi lahan ini menyebabkan semakin mengecilnya kepemilikan lahan yang juga berdampak terhadap rendahnya pendapatan petani padi sawah, sedangkan biaya pengeluaran petani untuk memenuhi kebutuhan hidup yang semakin tinggi. Berdasarkan latar belakang diatas, maka perlu dilakukan kajian analisis luas lahan minimum untuk memenuhi kebutuhan petani padi sawah di Kecamatan Jayapura Kabupaten OKU Timur.

\section{METODE PENELITIAN}

Metode yang digunakan dalam penelitian ini adalah metode survey, dengan metode penarikan contoh yang digunakan dalam penelitian ini adalah metode penarikan contoh acak berlapis tak berimbang (Proportionated Stratified Random Sampling) dengan kriteria yang dipakai berupa kriteria luas lahan, dapat dilihat pada tabel 3.

Penelitian dilakukan di Kecamatan Jayapura Kabupaten OKU Timur pada bulan November hingga Desember 2018. Tabel 3 menunjukkan bahwa Kecamatan Jayapura memiliki populasi petani sebanyak 247 petani padi sawah (non irigasi), dan jumlah sampel yang dijadikan dalam penelitian adalah sebanyak 30 petani atau $12,15 \%$ dari total populasi. Data yang diperoleh dalam penelitian ini terdiri dari data kualitatif dan data kuantitatif, kemudian diolah menggunakan tabulasi dan pendekatan matematis.

\section{Analisis Usahatani Padi Sawah}

Untuk menjawab permasalahan pertama penelitian, digunakan analisis usahatani padi sawah, se-

Tabel 3. Jumlah populasi dan sampel petani

\begin{tabular}{|c|c|c|c|c|}
\hline No & Luas lahan (Ha) & Populasi & Sampel & $\%$ \\
\hline 1 & 0,25 & 113 & 10 & 8,85 \\
\hline 2 & 0,50 & 41 & 5 & 12,19 \\
\hline 3 & 0,75 & 37 & 5 & 13,51 \\
\hline 4 & 1,00 & 16 & 2 & 12,50 \\
\hline 5 & 1,25 & 10 & 2 & 20,00 \\
\hline 6 & 1,50 & 14 & 2 & 14,28 \\
\hline 7 & 1,75 & 7 & 2 & 28,57 \\
\hline \multirow[t]{2}{*}{8} & 2,00 & 9 & 2 & 22,22 \\
\hline & Tota & 247 & 30 & 12 \\
\hline
\end{tabular}

Sumber: Kantor Kecamatan Jayapura, 2017 hingga dapat diketahui berapa besar pendapatan yang diperoleh dari usahatani padi sawah dalam satu musim tanam. Biaya merupakan penjumlahan antara biaya tetap dan biaya variabel yang dikeluarkan selama satu musim tanam padi sawah. Secara matematis dituliskan sebagai berikut :

Dimana :

$$
\mathrm{Bp}=\mathrm{Bt}+\mathrm{Bv}
$$

$$
\begin{array}{ll}
\mathrm{Bp} & =\text { Biaya produksi }(\mathrm{Rp} / \mathrm{mt}) \\
\mathrm{Bt} & =\text { Biaya tetap }(\mathrm{Rp} / \mathrm{mt}) \\
\mathrm{Bv} & =\text { Biaya variabel }(\mathrm{Rp} / \mathrm{mt})
\end{array}
$$

Pendapatan merupakan selisih antara total penerimaan dengan total biaya. Secara matematis dituliskan sebagai berikut :

Dimana :

$$
\mathrm{Tpd}=\mathrm{Tpn}-\mathrm{Bp}
$$

$$
\begin{array}{ll}
\text { Tpd } & =\text { Total pendapatan }(\mathrm{Rp} / \mathrm{mt}) \\
\mathrm{Tpn} & =\text { Total penerimaan }(\mathrm{Rp} / \mathrm{mt}) \\
\mathrm{Bp} & =\text { Biaya produksi }(\mathrm{Rp} / \mathrm{mt})
\end{array}
$$

\section{Analisis Pengeluaran Petani}

Pengeluaran petani yang dimaksud adalah biaya yang dikeluarkan untuk kebutuhan hidup dalam jangka waktu satu tahun yang terdiri dari pengeluaran pangan dan pengeluaran nonpangan yang dinyatakan dalam rupiah per tahun. Total pengeluaran petani dapat dirumuskan sebagai berikut:

Dimana:

$$
\mathrm{Tp}=\mathrm{Pp}+\mathrm{Pn}
$$

$\mathrm{Tp}=$ Total pengeluaran petani (Rp/Mt)

$\mathrm{Pp}=$ Pengeluaran untuk pangan (Rp/Mt)

$\mathrm{Pn}=$ Pengeluaran untuk nonpangan (Rp/Mt)

Model pendekatan atau kerangka pikir penelitian ditunjukkan pada Gambar 1 berikut ini :

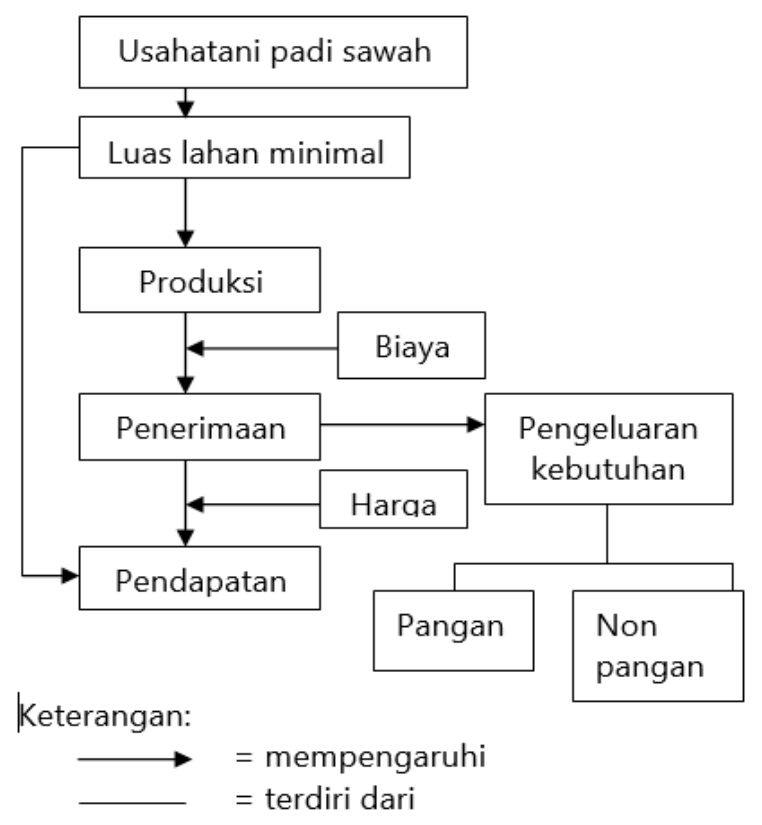

Gambar 1. Model pendekatan penelitian 
Gambar 1 menunjukkan model pendekatan atau kerangka pikir penelitian, dimana analisis dimulai dengan menghitung penerimaan kemudian pendapatan petani padi sawah di Kecamatan Jayapura Kabupaten OKU Timur. Variabel penerimaan dan pendapatan kemudian menjadi pembanding untuk menganalisis luasan lahan minimum yang harus dimiliki petani padi sawah agar dapat memenuhi kebutuhan hidupnya.

\section{Analisis Luas Lahan Minimum Untuk Memenuhi Kebutuhan Petani Padi Sawah}

Analisis luasan lahan minimum yang harus dimilik petani padi sawah di Kecamatan Jayapura Kabupaten OKU Timur, agar dapat memenuhi kebutuhan hidupnya dapat dianalisis dengan menggunakan pendekatan seperti yang ditunjukkan pada Tabel 4 berikut ini :

Tabel 4. Rumus simulasi secara matematis yang membandingkan luas lahan, pendapatan, dan pengeluaran petani.

\begin{tabular}{lcccc}
\hline No & $\begin{array}{c}\text { Luas lahan } \\
(\mathrm{Ha})\end{array}$ & $\begin{array}{c}\text { Pendapatan } \\
(\mathrm{Rp} / \mathrm{mt})\end{array}$ & $\begin{array}{c}\text { Pengeluaran } \\
(\mathrm{Rp} / \mathrm{mt})\end{array}$ & $\begin{array}{c}\text { Ketercapaian } \\
\text { Jika pendapatan> } \\
\text { pengeluaran }\end{array}$ \\
\hline 1. & 0,25 & & \\
2. & 0,50 & & \\
3. & 0,75 & & \\
4. & 1,00 & & \\
5. & 1,25 & & \\
6. & 1,50 & & \\
7. & 1,75 & & \\
8. & 2,00 & & \\
\hline
\end{tabular}

\section{HASIL DAN PEMBAHASAN}

\section{Pendapatan Petani Padi Sawah}

Pendapatan Petani padi sawah adalah selisih antara besarnya penerimaan usahatani dengan biaya yang dikeluarkan sebagai biaya produksi dalam suatu produksi. Besarnya pendapatan yang diterima petani dapat dilihat pada Tabel 4 berikut ini:

Tabel 4. Pendapatan petani padi sawah

\begin{tabular}{lcrcr}
\hline No & $\begin{array}{c}\text { Luas lahan } \\
(\mathrm{Ha})\end{array}$ & $\begin{array}{c}\text { Penerimaan } \\
(\mathrm{Rp} / \mathrm{mt})\end{array}$ & $\begin{array}{c}\text { Biaya pro- } \\
\text { duksi (Rp/ } \\
\mathrm{mt})\end{array}$ & $\begin{array}{c}\text { Pendapatan } \\
(\mathrm{Rp} / \mathrm{mt})\end{array}$ \\
\hline 1 & 0,25 & 6.401 .000 & 2.548 .250 & 3.852 .750 \\
2 & 0,50 & 11.953 .220 & 4.555 .000 & 7.398 .220 \\
3 & 0,75 & 19.769 .100 & 6.732 .000 & 13.037 .100 \\
4 & 1,00 & 25.065 .650 & 8.274 .000 & 16.791 .050 \\
5 & 1,25 & 31.598 .000 & 10.351 .000 & 21.247 .000 \\
6 & 1,50 & 37.795 .500 & 12.270 .250 & 25.525 .250 \\
7 & 1,75 & 43.092 .050 & 13.725 .250 & 29.366 .800 \\
8 & 2,00 & 47.804 .000 & 15.419 .000 & 32.385 .000 \\
\hline
\end{tabular}

Sumber : Hasil olahan data primer (2018)

\section{Pengeluaran petani}

Besaran konsumsi petani dibagi menjadi enam kelompok, yaitu pengeluaran untuk makanan, non makanan/sandang, pendidikan, kesehatan, pengeluaran sosial dan kebutuhan untuk usahatani musim berikutnya. Tingkat pengeluaran pada keenam kelompok untuk masing-masing petani berbeda, sesuai dengan luas penguasaan lahan masing-masing petani. Pada umumnya, besarnya nilai pengeluaran petani di pedesaan bervariasi sesuai dengan besarnya pendapatan yang mereka peroleh. Pengeluaran petani di Kecamatan Jayapura dapat dilihat pada Tabel 5 berikut ini :

Tabel 5. Pengeluaran petani berdasarkan luas lahan yang dimiliki petani $(\mathrm{Ha})$

\begin{tabular}{ccc}
\hline No & Luas lahan $(\mathrm{Ha})$ & Pengeluaran petani $(\mathrm{Rp} / \mathrm{mt})$ \\
\hline 1 & 0,25 & 9.830 .250 \\
2 & 0,50 & 11.900 .000 \\
3 & 0,75 & 14.516 .000 \\
4 & 1,00 & 16.509 .000 \\
5 & 1,25 & 20.620 .500 \\
6 & 1,50 & 21.450 .250 \\
7 & 1,75 & 23.870 .250 \\
8 & 2,00 & 27.495 .000
\end{tabular}

Sumber : Hasil olahan data primer (2018)

Tabel 5 menunjukkan bahwa semakin luas lahan yang dimiliki petani, semakin besar pengeluaran untuk kebutuhan hidupnya. Hal ini menunjukkan bahwa petani padi sawah di Kecamatan Jayapura Kabupaten OKU Timur rata-rata masih petani tradisional yang menghabiskan sebagian besar pendapatannya untuk kebutuhan hidup.

\section{Analisis kebutuhan lahan minimum untuk memenuhi kebutuhan hidup petani}

Kebutuhan lahan minimum untuk memenuhi kebutuhan hidup petani dianalisis dengan membandingkan pendapatan terhadap pengeluaran petani padi sawah. Jika pendapatan petani lebih besar dari pengeluaran, maka kebutuhan petani sudah tercapai, sedangkan jika pendapatan petani lebih kecil daripada pengeluarannya, maka hasil dari lahan yang dimiliki petani belum mampu memenuhi kebutuhan hidupnya. Hal ini ditunjukkan pada Tabel 6 berikut ini :

Tabel 6. Analisis kebutuhan lahan minimum untuk memenuhi kebutuhan petani.

\begin{tabular}{lrrrl}
\hline No & $\begin{array}{l}\text { Luas la- } \\
\text { han (Ha) }\end{array}$ & $\begin{array}{l}\text { Pendapatan } \\
(\mathrm{Rp} / \mathrm{mt})\end{array}$ & $\begin{array}{l}\text { Pengelu } \\
\text { aran } \\
\mathrm{mt})\end{array}$ & $\begin{array}{l}\text { Ketercapaian } \\
\text { Jika pendapatan> } \\
\text { Pengeluaran }\end{array}$ \\
\hline 1 & 0,25 & 3.852 .750 & 9.830 .250 & Belum tercapai \\
2 & 0,50 & 7.398 .220 & 11.900 .000 & Belum tercapai \\
3 & 0,75 & 13.037 .100 & 14.516 .000 & Belum tercapai \\
4 & 1,00 & 16.791 .050 & 16.509 .000 & Tercapai \\
5 & 1,25 & 21.247 .000 & 20.620 .500 & Tercapai \\
6 & 1,50 & 25.525 .250 & 21.450 .250 & Tercapai \\
7 & 1,75 & 29.366 .800 & 23.870 .250 & Tercapai \\
8 & 2,00 & 32.385 .000 & 27.495 .000 & Tercapai \\
\hline & Rata-rata & 15.057 .083 & & \\
\hline
\end{tabular}

Sumber: Hasil olahan data primer (2018) 
Tabel 6 menunjukkan bahwa petani padi sawah yang memiliki luas lahan 0,25 hingga 0,75 ha belum mampu memenuhi kebutuhan hidupnya, hal ini ditunjukkan dengan tingginya pengeluaran petani untuk kebutuhan hidup dibandingkan pendapatan yang diperolehnya dari usahatani padi. Luas lahan minimum yang harus dimiliki petani untuk mampu memenuhi kebutuhan hidupnya adalah satu hingga dua hektar. Senada dengan hasil penelitian ini, Gaol (2011) dalam penelitiannya tentang Analisis Luas Lahan Minimum untuk Peningkatan Kesejahteraan Petani Padi Sawah Studi Kasus Desa Cinta Damai Kecamatan Percut Sei Tuan Kabupaten Deli Serdang, menunjukkan bahwa tingkat pendapatan di daerah penelitian sangat rendah dan bervariasi pada masing-masing strata. Berdasarkan pola pengeluaran petani, pengeluaran terbanyak digunakan untuk kebutuhan makanan dan kebutuhan non makanan, dan pengeluaran terbanyak untuk kebutuhan pendidikan. Luas lahan minimum yang harus diusahakan petani untuk dapat memenuhi kebutuhan hidupnya di daerah penelitian adalah 0,66 Ha dan tingkat kesejahteraan petani di lokasi penelitian belum terpenuhi.

Penelitian sejenis, menurut Nazam, M., et al (2016) menyatakan bahwa luas lahan minimal untuk memenuhi kebutuhan hidup layak petani padi sawah adalah 0,73 ha sedangkan luas lahan garapan rata-rata sebesar 0,48 ha. Kontribusi pendapatan usahatani padi sawah terhadap kebutuhan hidup layak sebesar 55,73 persen.

Susilowati \& Maulana (2012), menyatakan bahwa petani harus memiliki lahan seluas 0,65 hektar untuk tanaman padi, 1,12 hektar untuk jagung, dan 0,74 hektar untuk kedelai, atau 0,5 hektar secara umum menurut standar BPS untuk mencapai kesejahteraan petani. Dengan lahan yang terbatas ini, mengakibatkan petani tidak bisa berbuat leluasa di lahan mereka untuk menanam berbagai produk-produk pertanian. Berkaitan dengan kebutuhan lahan untuk kehidupan petani, maka Widodo (2017) menyatakan bahwa tanah yang dikuasai oleh petani dan diretribusikan khusus pada petani miskin harus dipandang sebagai modal utama sehingga petani mampu menaikkan taraf hidupnya. Selanjutnya Mulyani (2017) dalam hasil penelitiannya menyatakan bahwa kebutuhan akan ketersediaan lahan bagi petani sangatlah penting, terlebih untuk ekstensifikasi BBSDLP., (2011) menyatakan bahwa lahan pertanian menjadi salah satu faktor penentu keberhasilan untuk mempertahankan swasembada pangan dan untuk menjadikan Indonesia sebagai lumbung pangan dunia menjelang tahun 2045.

Beberapa penelitian sejenis lainnya dikemukakan oleh Hasbullah, S (2013), dalam penelitiannya tentang analisis kebutuhan luas lahan pertanian pangan sebagai dasar perencanaan dan pengembangan lahan pertanian berkelanjutan di Kabupaten Konawe Selatan menyatakan bahwa analisis kebutuhan ukuran lahan usahatani minimal dan titik impas usahatani per rumah tangga tani dan saran kebijakan untuk meningkatkan pendapatan dan kesejahteraan rumah tangga petani adalah di atas 0,5 ha. Jumlah petani yang menguasai lahan $<0,5$ ha, meningkat dari 45,3 persen menjadi 56,4 persen, dan rata-rata luas penguasaan lahan sawah semakin sempit karena alih fungsi lahan pertanian yang marak terjadi di Kabupaten ini. Senada dengan hasil penelitian, Suprastyo, D (2018) juga menyatakan bahwa ketimpangan pemilikan lahan terjadi karena semakin mengecilnya lahan yang dikuasai dan dimiliki petani akibat pesatnya pembangunan dan pertambahan jumlah penduduk yang mengarah kepada ketidakadilan.

Konversi lahan sawah ke penggunaan nonpertanian seperti kompleks perumahan, kawasan industri, kawasan perdagangan, dan sarana publik dapat menimbulkan dampak negatif secara ekonomi, sosial, dan lingkungan. Bagi ketahanan pangan nasional, konversi lahan sawah merupakan ancaman yang serius, mengingat konversi lahan tersebut sulit dihindari sementara dampak yang ditimbulkan terhadap masalah pangan bersifat permanen, kumulatif, dan progresif (Irawan, B., 2016). Selanjutnya menurut Ditjen PSP (2013) gejala seperti ini dapat diketahui dari akumulasi lahan pertanian yang berlebihan, pemecahan bidang lahan pertanian, dan perubahan penggunaan lahan pertanian ke non pertanian, sehingga pemilikan lahan pertanian semakin menyempit bahkan mencapai luas lahan yang kurang dari 0,5 ha (petani gurem). Keadaan luasan lahan yang semakin kecil yang bisa diusahakan petani tentu saja berpengaruh terhadap kemampuan petani dalam memenuhi kebutuhan hidup rumahtangganya. Pradipta, M., (2018) dalam penelitiannya tentang tingkat kesejahteraan keluarga petani padi di Desa Sumberagung Kabupaten Sleman, jika dilihat dari luas lahan garapan keluarga petani, baik itu lahan sendiri atau lahan milik orang lain, memiliki perbedaan yang signifikan. Semakin luas lahan garapan keluarga petani padi, semakin tinggi pula kesejahteraan keluarganya. Lahan garapan yang sempit menjadi penyebab keluarga petani kesulitan untuk mencapai tingkat kesejahteraan yang baik.

\section{KESIMPULAN DAN SARAN}

Kesimpulan dari penelitian ini adalah luasan lahan minimum yang harus dimiliki petani padi sawah di Kecamatan Jayapura Kabupaten OKU Timur agar dapat memenuhi kebutuhan hidupnya ada- 
162 | Nazalina, A., dkk. Evaluasi Sarana Produksi Pangan Industri Tahu...

lah sebesar satu hektar dengan pendapatan sebesar Rp.16.791.050/mt dan pengeluaran sebesar Rp.16.509.000/mt.

Rekomendasi yang dapat diberikan pada petani yang memiliki lahan kurang dari satu hektar, untuk dapat mengoptimalkan lahan yang dimiliki dengan diversifikasi tanaman lainnya selain padi. Pada pemerintah diharapkan mampu membuka lapangan kerja di pedesaan untuk membantu petani yang memiliki lahan sempit.

\section{DAFTAR PUSTAKA}

Azadi H, Ho P, Hasfiati L., (2010). Agricultural Land Conversion Drivers: A Comparison Between Less Developed, Developing and Developed Countries. Land Degradadation and Development Journal. Wiley Online Library (wileyonlinelibrary.com). DOI: 10.1002/ Idr.1037.

BBSDLP., (2011). Petunjuk Teknis Evaluasi Lahan untuk Komoditas Pertanian. Balai Besar Penelitian dan Pengembangan Sumberdaya Lahan Pertanian. Bogor.

BPS OKU Timur., (2017). OKU Timur dalam Angka. Martapura.

BPS Sumsel., (2017). Sumatera Selatan Dalam Angka. Palembang.

BPS., (2013). Badan Pusat Statistik, Sensus Pertanian. Jakarta.

Ditjen Tanaman Pangan., (2016). Kebutuhan Produski, Konversi, dan Kebutuhan Lahan untuk Perluasan Areal Sawah. Direktorat Jenderal Tanaman Pangan. (Tidak dipublikasi). Jakarta.

Ditjen PSP., (2013). Potensi Alih Fungsi Lahan Akibat Tidak Ditetapkan LP2B dalam RTRW Kabupaten/Kota. Direktorat Jenderal Prasarana dan Sarana Pertanian. Jakarta.

Gaol L., (2011). Analisis Luas Lahan Minimum Petani Padi Sawah di Desa Cinta Damai Kecamatan Percut Sei Tuan Kabupaten Deli Serdang. (dipublikasikan). Medan.

Hasbullah, S., Tufaila, M., Yunus, L., Karim, J dan Rauf, M.A., (2013). Analisis Kebutuhan Luas Lahan Pertanian Pangan sebagai Dasar Perencanaan dan Pengembangan Lahan Pertanian Berkelanjutan di Kabupaten Konawe Selatan. Prosiding Seminar Nasional Perencanaan Pembangunan Inklusif Desa dan Kota. Universitas Andalas.
Irawan B., (2016). Konversi Lahan Sawah: Potensi Dampak, Pola Pemanfaatannya dan Faktor Determinan. Forum Penelitan Agro Ekonomi Jilid 23, Terbitan 1.

Mulyani, A dan Agus, F., (2017). Kebutuhan dan Ketersediaan Lahan Cadangan untuk Mewujudkan Cita-cita Indonesia sebagai Lumbung Pangan Dunia 2045. Jurnal Analisis Kebijakan Pertanian, Vol 15 No.1. Jakarta.

Nazam, M., Sabihan, S., Pramudya, B., Widiatmaka., Rusastra I, W., (2016). Penetapan Luas Lahan Optimal untuk Usahatani Padi Sawah Mendukung Kemandirian Pangan Berkelanjutan di Nusa Tenggara Barat. Jurnal Agro Ekonomi. Vol 24 No. 2. IPB. Bogor.

Putri, R.Z., (2015). Analisis Penyebab Alih Fungsi Lahan Pertanian ke Lahan Non Pertanian Kabupaten/Kota di Propinsi Jawa Tengah. Jurnal Eko Regional Vol 10 No.1. Jakarta.

Pradipta, P., (2018). Tingkat Kesejahteraan Keluarga Petani Padi di Desa Sumberagung Jurnal Pendidikan dan Ekonomi, Vol 7 No.1. Fakultas Ekonomi, Universitas Negeri Yogyakarta. Yogyakarta.

Suprastyo, D., (2018). Analisis Distribusi Pemilikan Lahan Pertanian dan Pendapatan Usahatani Padi di Kabupaten Karawang. Thesis. Dipublikasikan. IPB. Bogor.

Susilowati, H.S.,dan Maulana, M., (2016). Luas Lahan Usahatani dan Kesejahteraan Petani : Eksistensi Petani Gurem dan Urgensi Kebijakan Reforma Agraria. Jurnal Litbang Pertanian. Pusat Sosial Ekonomi dan Kebijakan Pertanian. Bogor

Soekartawi., (2013). Agribisnis, Teori dan Aplikasinya. Raja Grafindo Persada. Jakarta.

Tim Penulis Monografi Kecamatan Jayapura., (2017). Monografi Kecamatan Jayapura, Kabupaten OKU Timur. Martapura.

UPTD Tanaman Pangan dan Hortikultura., (2017). UPTD Jayapura, Kabupaten OKU Timur. Martapura.

Widodo, S., (2017). A Critical Review of Indonesia's Agrarian Reform Policy. Journal of Regional and City Planning Vol. 28, No. 3, December 2017 DOI: 10.5614/jrcp.2017.28.3.4 